\title{
The EUMETNET AutoPollen programme: establishing a prototype automatic pollen monitoring network in Europe
}

\author{
Bernard Clot • Stefan Gilge • Lenka Hajkova • Donát Magyar • \\ Helfried Scheifinger $\cdot$ Mikhail Sofiev $\cdot$ Fabienne Bütler $\cdot$ Fiona Tummon $(\mathbb{C}$
}

Received: 23 June 2020/ Accepted: 8 October 2020

(C) The Author(s) 2020

\begin{abstract}
Operational pollen monitoring networks have developed across Europe, and the world more generally, in response to the increasing prevalence of pollen allergy and asthma. Routine pollen observations are in large part currently still based on timeintensive manual techniques developed in the 1950s. These methods suffer from low temporal resolution and long delays in data availability. Recent technological developments are revolutionising the field making real-time high-temporal resolution measurements possible. This paper describes the rationale
\end{abstract}

B. Clot · F. Bütler · F. Tummon ( $\square)$

Federal Office of Meteorology and Climatology

MeteoSwiss, Payerne, Switzerland

e-mail: fiona.tummon@meteoswiss.ch

S. Gilge

German Meteorological Service, Freiburg-im-Breisgau,

Germany

L. Hajkova

Czech Hydrometeorological Institute, Prague, Czech

Republic

D. Magyar

National Public Health Center, Budapest, Hungary

H. Scheifinger

Austrian Central Institute for Meteorology and

Geodynamics, Vienna, Austria

M. Sofiev

Finnish Meteorological Institute, Helsinki, Finland behind the EUMETNET AutoPollen programme, which aims to develop a prototype automatic pollen monitoring network across Europe. We provide a brief description of the current state-of-the-art, then an overview of new technologies, and finally the main tasks of the AutoPollen programme.

Keywords Pollen monitoring network - Automatic . Real-time · AutoPollen

\section{Introduction}

Over the past 30 years, the prevalence of pollen allergy and asthma in Europe has increased fourfold, now affecting between 15 and $40 \%$ of the population. This level continues to increase, with approximately $25 \%$ of the adult population being affected but nearly $30-40 \%$ of children having allergies (Laatikainen et al. 2011; Rönmark et al. 2009). The reasons for this increase remain elusive but are likely a complex combination of various environmental and lifestyle factors, including increased population susceptibility and co-exposure to anthropogenic pollutants (Laatikainen et al. 2011; Pearce et al. 2007; Sunyer et al. 2004). A range of recent studies has also shown that climate change will worsen the impact of allergy in the coming decades. This is due to a combination of factors: longer flowering periods resulting from 
temperature increases, more plant productivity and higher pollen emissions due to increased $\mathrm{CO}_{2}$ concentrations, increased allergen concentrations in pollen grains because of various stress factors such as heat or air pollution (Damialis et al. 2019; Ziska et al, 2019; Lake et al. 2017; D'amato et al. 2014; IPCC 2007; Riedl and Diaz-Sanchez 2005), and the extension of ranges of various introduced allergenic plant species, such as ornamentals or invasives (Schaffner et al. 2020; Lake et al. 2017; Beggs 2010; D'Amato and Cecchi 2008).

The burden on the European public health system is significant, with the direct and indirect health costs related to asthma and insufficiently treated allergies estimated at nearly $€ 50$ billion/year and $€ 50-150$ billion/year, respectively (Zuberbier et al. 2014; ERS 2013). Furthermore, these issues are a major concern to the European public, with $87 \%$ of Europeans seeing asthma and allergy prevalence as a serious or very serious problem-on par with cardiovascular and respiratory diseases (ERS 2013). Improved monitoring of airborne pollen is thus vital to ensure better prevention, diagnosis, and treatment of allergy-related health problems as well as to reduce associated costs. The current technology used across Europe dates back to the 1950s (Hirst 1952) and suffers in particular from low time resolution (usually daily averages, 2-hourly averages are possible, however, with significantly larger uncertainties) and large delays in data availability (typically with data from the previous week available once a week, with at least one day delay). The advent of real-time pollen monitoring, and in particular the high time-resolution of these observations, is revolutionising the information available to allergy sufferers and medical practitioners, as well as for pollen forecasts. Better diagnosis and treatment of allergies will significantly reduce the burden on the European health system and improve quality of life for an ever-increasing proportion of the population. New avenues for research, clinical studies, and education will also open up, as will the potential for synergies with the air quality and aerosol communities, resulting in an improvement of services and additional savings (Oberpriller et al. 2017).

While in its infancy, the technology behind automatic pollen monitoring is rapidly developing. At this early stage, it is essential that the opportunity be taken to establish a standardised European network that provides information corresponding to users' needs and which avoids unnecessary duplication or harmonisation efforts in future. The EUMETNET AutoPollen programme aims to fulfil this task in a collaborative, efficient, and effective manner, covering all aspects of the information chain from the standardisation of measurements through to the provision of products codesigned with end-users.

This paper describes the rationale behind a European automatic pollen monitoring network, first providing a brief description of the current state-ofthe-art, then an overview of new technologies, and finally the main tasks of the EUMETNET AutoPollen programme.

\section{State-of-the-art: a critical understanding of current pollen monitoring}

Airborne pollen grains are large particles, typically between 10 and $100 \mu \mathrm{m}$ in diameter, and thus not easy to capture because of their large inertia and high sedimentation rates, as well as the fact that they tend to stick to the side walls of the monitoring instruments. Relative to other aerosol they are also present in very low concentrations, ranging from a few units to a few thousand grains per cubic metre, meaning that high volume sampling is required to ensure measurements are representative. Furthermore, it is essential that each particle is identified precisely, since allergies are provoked by different allergens present in the pollen of specific plant taxa.

The present standard method for sampling airborne pollen is based on volumetric impactors that allow up to seven days of continuous sampling (Hirst 1952). Ten litres of air per minute are sucked into the device and particles impact onto a sticky strip that is mounted on a rotating drum. The drum is usually replaced once a week, after which the strip is analysed in a timeconsuming manual process in the laboratory. This method results in a delay of one to nine days between sampling and data availability, and requires specialised staff, which is expensive and thus limits the density of pollen monitoring networks. The resultant data also suffer from high levels of uncertainty because of the limited sampling area over which pollen is counted (Galan et al. 2014), and several technical and methodological issues still need to be systematically addressed (e.g., Oteros et al. 2017). A Global Earth Observation report underlined that 
"these methods need to be improved, aiming at more accurate and advanced forecasting" (GEO 2009). As such, there is no "golden standard" in terms of pollen observations and no absolute reference against which new automatic measurements can be compared.

Manual pollen monitoring networks exist in almost all European countries (Buters et al. 2018), maintained by different institutions including national meteorological and hydrological services, public health institutes, universities, and private organisations. They nearly all participate in the European Aeroallergen Network (www.polleninfo.org), a voluntary association of pollen monitoring networks in Europe and beyond. This network maintains a common pollen database that currently includes data from Hirst-type instruments from over 300 sites. The network is essentially run on a private basis with next to no public funding and since the data owners are in many cases private organisations, most of the data are not freely available for the public, forecasts, or research purposes.

\section{Technological breakthroughs and automatic pollen monitoring}

At a time when so much information is available online immediately, publishing pollen data from up to nine days ago seems like an anachronism and operators of pollen monitoring networks are frequently approached by end-users to ask why this is the case. Furthermore, only real-time data can be integrated into numerical forecast models, which would help to considerably improve on how current forecasts are produced. Over the past few years, a handful of automatic pollen monitoring systems have become commercially available. These technologies exploit two main techniques: image recognition and/or airflow cytometry (Huffman et al. 2019).

Image recognition is used in the BAA500 (Helmut Hund, www.hund.de) (Oteros et al. 2015; Ronneberger et al. 2002), in which an air-flow deposits particles on a surface which is then analysed by microscope imaging. Software then counts and identifies pollen taxa. The recently launched ePIN network in Bavaria, Germany, makes use of this technology and publishes 3-hourly pollen concentration information on its website continuously (Oteros et al. 2019). Another instrument, based on a somewhat similar method, is the PollenSense Airborne Particulate Sensor (APS) (Lucas et al. 2018), which also uses an image recognition system to identify pollen particles.

A number of instruments use air-flow cytometry, including the KH3000 (Yamatronics, www. yamatronics.com) (Kawashima et al. 2017, 2007). This robust instrument has been used in the Japanese Hanakosan monitoring network since 2002, using forward- and side-scattering measurements to provide information about levels of Japanese Cedar pollen in winter. Other instruments that perform in situ measurements of pollen particles include the Droplet Measurement Technologies WIBS-Neo (DMT; www. dropletmeasurement.com) (Savage et al. 2017; O'Connor et al. 2014), Plair Rapid-E (www.plair.ch) (Šauliene et al. 2019; Crouzy et al. 2016), and Swisens Poleno (www.swisens.ch) (Sauvageat et al. 2020). All three instruments use lasers at various wavelengths to produce scattering and fluorescence signals which are used to identify particles, while the Swisens Poleno additionally takes holographic images.

Prices for these instruments range from a few thousand to more than a hundred thousand Euros. They also vary significantly in their characteristics and capabilities. In particular, not all have demonstrated a real ability to identify different pollen taxa nor has the full potential of others been reached. Several other instruments are still under development, using technology such as liquid cytometry (Huffman et al. 2019). The Plair Rapid-E is currently operational in a prototype network between Serbia and Croatia, as part of the RealforAll project (www.realforall.com), while the Swisens Poleno is being deployed across the Swiss operational monitoring network. A number of research instruments are also located at various sites across Europe. A world map of the pollen monitoring stations, including automatic systems, is shown on the website of the European Academy of Allergy and Clinical immunology (www.eaaci.org/19-activities/ task-forces/4342-pollen-monitoring-stations-of-theworld.html).

Whichever technique is used, the advent of automatic pollen monitoring, and in particular, the high temporal-resolution and near real-time availability of these observations, will revolutionise the information available to allergy sufferers and the public health area, as well as for pollen forecasts. The higher temporal resolution of these data will also help to provide a much deeper understanding of 
aerobiological phenomena and the factors, such as meteorology, influencing them (e.g. Chappuis et al. 2019). The potential of some instruments to analyse aerosol other than pollen (e.g. spores or fine particulate matter) is particularly of interest since it may lead to synergies with the air quality and agricultural communities, e.g. for maintaining monitoring networks and exchanging data and information, thus improving the provision of services and resulting in additional savings. Table 1 summarises the main differences between manual and automatic pollen counting methods.

\section{The EUMETNET AutoPollen programme 2018-2022}

In response to the emergence of new technologies for real-time pollen observations and the growing needs of the population, the AutoPollen programme was established to serve as a platform to develop a
European automatic pollen monitoring network. The programme is part of EUMETNET, the grouping of European national meteorological and hydrological services (NMHSs), and represents a unique opportunity to significantly contribute to public health and develop the level of service provided across Europe from the very start of the use of automatic pollen monitoring systems. EUMETNET provides an optimal framework for the AutoPollen programme given the collective infrastructure, knowledge, and experience that is held by NHMSs. This includes existing infrastructure and expertise in maintaining monitoring networks, acquiring and exchanging huge amounts of data, and producing pollen forecasts using numerical models.

The ultimate goal of AutoPollen is not only to establish long-term automatic pollen monitoring across Europe, but also to provide pollen observations and model forecasts to the public, medical practitioners, and health authorities for near real-time decision support (e.g. Gilles et al. 2020). The cross-border

Table 1 Comparison of manual and automatic pollen monitoring methods

\begin{tabular}{|c|c|c|}
\hline & Manual Hirst-type systems & Automatic systems (instrument dependent) \\
\hline Strengths & Expertise and critical analysis & Real-time availability, high temporal resolution \\
\hline $\begin{array}{l}\text { Data } \\
\text { availability }\end{array}$ & 1-9 days delay & Near real-time (from minutes up to $6 \mathrm{~h}$ ) \\
\hline $\begin{array}{l}\text { Sampling } \\
\text { resolution }\end{array}$ & $\begin{array}{l}\text { Usually daily averages, although up to 2-hourly } \\
\text { resolution can be obtained (with associated error } \\
\text { depending on the proportion of the slide counted) }\end{array}$ & From minutes up to $3 \mathrm{~h}$ \\
\hline Logistics & $\begin{array}{l}\text { Intervention on site minimum once a week for the drum } \\
\text { exchange. A laboratory is required to prepare the } \\
\text { sampling drums and for the pollen counting. At } \\
\text { monitoring stations without a laboratory (and trained } \\
\text { personnel), shipping is needed to transport samples to } \\
\text { the laboratory (i.e. extra delay and cost) }\end{array}$ & $\begin{array}{l}\text { No intervention on site for operational activities required, } \\
\text { except for occasional maintenance (usually 1-2 times } \\
\text { per year). Two devices, the BAA500 and APS, do, } \\
\text { however, require the replacement of consumables every } \\
3-8 \text { weeks }\end{array}$ \\
\hline $\begin{array}{l}\text { Number of } \\
\text { sites }\end{array}$ & $\begin{array}{l}\text { Pollen counting is time-consuming and requires } \\
\text { specialised staff thus limiting the number of monitoring } \\
\text { sites }\end{array}$ & $\begin{array}{l}\text { Denser spatial coverage is possible, with the number of } \\
\text { sites being limited by the device costs rather than staff } \\
\text { availability and costs }\end{array}$ \\
\hline $\begin{array}{l}\text { Data } \\
\text { availability }\end{array}$ & $\begin{array}{l}\text { Manual pollen counting takes between } 10 \text { and } 120 \text { min } \\
\text { for } 1 \text { day for } 1 \text { site. Daily average values are usually } \\
\text { made available once per week }\end{array}$ & $\begin{array}{l}\text { Pollen counting is automatic and data are available in } \\
\text { near real-time (delays of minutes- } 3 \mathrm{~h} \text { ) }\end{array}$ \\
\hline $\begin{array}{l}\text { Quality } \\
\text { control }\end{array}$ & Requires specialised staff, time-consuming & $\begin{array}{l}\text { Can be automatised to a certain degree, but may require } \\
\text { human intervention on occasion }\end{array}$ \\
\hline $\begin{array}{l}\text { Number of } \\
\text { species } \\
\text { identified }\end{array}$ & $\begin{array}{l}\text { Numerous pollen and spore taxa can be identified (more } \\
\text { than } 100 \text { pollen species, depending on the analyst's } \\
\text { experience) }\end{array}$ & $\begin{array}{l}\text { At least the main allergenic taxa, with possible extension } \\
\text { to additional pollen taxa and other particles (spores, air } \\
\text { pollution) in future }\end{array}$ \\
\hline Costs & Low initial investment, high personnel costs & $\begin{array}{l}\text { Higher initial investment, running costs estimated lower } \\
\text { or equivalent }\end{array}$ \\
\hline
\end{tabular}


nature of pollen dispersal (Mohanty et al. 2017; de Weger et al. 2016; Izquierdo et al. 2011; Rousseau et al. 2008) means that it is essential that the monitoring network extends across the entire European continent and which is why significant effort has been placed on involving participants from as many countries as possible (see Table 2 for the complete list of current participants). The participation of these groups is also vital since in most European countries, pollen monitoring networks are not operated by NMHSs or other governmental organisations, even if these institutes nearly all issue pollen forecasts. The availability of real-time pollen data from across the continent would significantly improve such forecasts, and it is thus likely that as the network grows, more and more of these governmental organisations would be willing to establish and operate automatic pollen monitors in their country. Personnel that are currently involved in repetitive manual pollen counting could be oriented towards developing and improving the quality of products providing pollen-related information and further develop research across a range of disciplines (Šantl-Temkiv et al. 2019). This represents a significant paradigm change compared to the present situation where monitoring networks are, in many countries, maintained by private organisations or universities with limited mandate or budget for such activities. The involvement of governmental organisations will help to ensure the long-term sustainability

Table 2 List of participants to the EUMETNET AutoPollen programme

\begin{tabular}{|c|c|c|}
\hline \multirow[t]{28}{*}{ Participants } & Country & Institution \\
\hline & Austria & Central Institute for Meteorology and Geodynamics (ZAMG) \\
\hline & Croatia & Croatian Meteorological and Hydrological Service (DHMZ) \\
\hline & Czech Republic & Czech HydroMeteorological Institute (CHMI) \\
\hline & Finland & Finnish Meteorological Institute (FMI) \\
\hline & Germany & German Meteorological Service (DWD) \\
\hline & Greece & Hellenic National Meteorological Service (HNMS) \\
\hline & Ireland & Met Éireann \\
\hline & Luxembourg & MeteoLux \\
\hline & Poland & Institute for Meteorology and Water Management (IMGW) \\
\hline & Slovenia & National Meteorological Service of Slovenia (ARSO) \\
\hline & Switzerland & Federal Office of Meteorology and Climatology MeteoSwiss \\
\hline & Belgium & Sciensano \\
\hline & France & ATMO France \\
\hline & France & Réseau National de Surveillance Aérobiologique (RNSA) \\
\hline & Germany & Bavarian State Office for Health and Food Safety (LGL) \\
\hline & Latvia & University of Latvia \\
\hline & Lithuania & Siauliai University \\
\hline & Portugal & Institute of Earth Sciences \\
\hline & Portugal & Portuguese Institute for the Sea and Atmosphere (IPMA) \\
\hline & Serbia & BioSense Institute \\
\hline & Spain & AEA - Spanish Aerobiology Network \\
\hline & Sweden & Swedish Museum of Natural History \\
\hline & Turkey & Bursa Uludag University \\
\hline & Ukraine & National Pirogov Memorial Medical University \\
\hline & United Kingdom & University of Worcester \\
\hline & International & EAS European Aerobiology Society \\
\hline & International & EFA European Federation of Allergy and Airways Diseases Patients' Association \\
\hline \multirow[t]{2}{*}{ Collaborations } & International & CAMS (Copernicus Atmospheric Monitoring Services), CAMS_23 \\
\hline & International & COST Action CA18226-New approaches in detection of pathogens and aeroallergens \\
\hline
\end{tabular}


of monitoring networks and the free, public availability of these observations.

\section{Tasks to be carried out}

The AutoPollen programme aims to cover the entire information chain from measurement through to communication of real-time pollen observations and forecasts. It will clarify the fundamentals of automatic pollen monitoring by proposing standards and measurement requirements, demonstrating the feasibility of a prototype European network by integrating ongoing and planned projects across the continent. The programme has been developed such that each step is addressed with several detailed reports or activities, which are outlined below.

\subsection{Technology and measurement methods}

The technology behind automatic pollen monitoring is still in its infancy and both the challenges and full potential of these measurements need to be completely understood. An intercomparison campaign to test the range of available automatic pollen monitors will be carried out in parallel with manual Hirst-type observations to compare how instruments function under different ambient conditions and to better understand limits of detection as well as levels of accuracy. Minimum requirements in terms of the pollen species to be identified will also need to be established. Furthermore, it is essential that the new methods are validated and a set of standards developed for automatic pollen measurements, as has been done for manual Hirst-type observations (CEN EN 16868:2019). Such standards will need to include a wide range of criteria including sampling height and volume, as well as calibration and maintenance standards. There needs to be common agreement across a future monitoring network for each of these aspects, all of which need to be fully documented from the start. Establishing these standards from the very beginning will prevent unnecessary duplication and harmonisation efforts in the future, thus saving considerable personnel and financial resources.

\subsection{Site selection and network design}

Similar to measurement standards, a set of criteria for optimal measuring sites will need to be developed as will a list of metadata to be reported at each site. The representativeness of each monitoring station will also need to be assessed and research into the best methods for doing this carried out. While the selection of individual measurement sites may depend on a number of local and regional factors, in particular vegetation, it is essential that the entire European network is designed in an intelligent way. This should ensure optimal spatial coverage and minimise related costs, all the while keeping in mind the importance of maintaining long-term records. A number of reference sites will also be established in different bioclimatic regions to provide the possibility to test and compare the various instruments available on the market. Such activities will serve to verify how different instruments operate in different climatic conditions and whether they are able to recognise, at least, the most important pollen present in the European atmosphere.

\subsection{Data format and exchange protocols}

To ensure data can be effectively shared, a uniform data format will need to be established, regardless of instrument or technology. Exchange protocols will also need to be developed to assure timely data availability, as will data quality control procedures, including how to quantify data quality. Existing infrastructure could be used to store and distribute data. Exploiting a joint European database would provide considerable savings, facilitating data exchange and large-scale data analysis. Such data exchange is vital also for numerical models, which require real-time observations to provide more accurate forecasts, as well as for other downstream products.

\subsection{Improvement of numerical forecast models}

At present, numerical forecast models use only historical climatologies, which are combined with current meteorology, to produce forecasts. However, the development of real-time pollen observations makes possible the integration of this information into numerical forecast models and, just as was the case for weather forecasts, is likely to vastly improve 
the quality of pollen predictions. Such forecasts play an integral role in the day-to-day management and treatment of pollen allergies and improvement in their accuracy could have large impacts on the quality of life of allergy-sufferers across Europe. It is only through developing a network of automatic pollen monitors across Europe that the full potential of these devices can be put to use in these models.

\subsection{Building a prototype network and assessing impacts}

The final step will be to establish a fully functional prototype network, bringing together all current and developing automatic pollen monitoring projects from across Europe. Participants will use knowledge established through the previous activities to better understand which technology is best adapted for their needs. They may also work together on joint projects, share experience and knowledge, and jointly develop infrastructure or tools, thus saving both time and money. Finally, it will be essential to evaluate the impact of the network and the improved information it provides on the quality of pollen forecasts, the services and new products made available to end-users, as well as on new research fields (e.g. plant and ecosystem sciences, phenology, etc.).

\section{Synergies and collaboration with partners}

Systematic pollen observations and related activities in the fields of public health, air quality modelling and forecasting, climate change assessment, etc., have a long history dating back to the middle of the twentieth century. There are established connections among the key players and the success of the AutoPollen programme depends on the involvement of these stakeholders, which include, amongst others:

- Copernicus Atmospheric Monitoring Service (CAMS; https://atmosphere.copernicus.eu) whose main objective is to provide operational forecasts and assessments of atmospheric state and composition. One of the major CAMS services is dedicated to European air quality, with pollen forecasting and assessment being one of the new frontiers (Sofiev et al. 2015, 2017; Sofiev 2019).
- The Cost Action ADOPT (new Approaches in Detection Of PaThogens and aeroallergens, CA18226) brings together an interdisciplinary network of experts involved in bioaerosol measurements, whether it is with standard manual methods or upcoming technologies. A main objective of the action is to stimulate research and development of both observation methods and numerical methods for big data analyses. There are many parallels between AutoPollen and ADOPT, and there is tight collaboration between the two projects on research activities.

- The European Academy of Allergy and Clinical Immunology (EAACI; www.eaaci.org) is an association aimed at promoting basic and clinical research; collecting, assessing, and disseminating scientific information; functioning as a scientific reference body for other scientific, health, and political organisations; encouraging and providing training and continuous education; as well as promoting good patient care in this important area of medicine. EAACI members are historically at the origin of the development of pollen monitoring networks and key users of pollen data.

- Manufacturers of automatic pollen devices. There are several companies that produce such instruments, and it is a domain in constant evolution. AutoPollen has active connections with these businesses and their integration into certain of the programme's tasks, for example, the intercomparison campaign, is essential.

Other stakeholders include various United Nations organisations such as the World Meteorological Organisation (WMO), World Health Organisation, and UN Environment.

\section{Perspectives for the future}

AutoPollen will establish a prototype automatic pollen monitoring network, covering the entire information chain from helping to advance observation techniques through to the final products for end-users. This growing network will likely be of hybrid form, incorporating a range of different devices and types of sites, from stations with just one monitor to larger "supersites" where a number of monitors are placed together. Such a network will benefit from the 
diversity of capacity across the different devices, helping, for example, to detect new species as climate change affects their ranges. AutoPollen will thus serve as a proof-of-concept and pave the way towards a sustainable automatic pollen monitoring network that provides data in near real-time to the public free of charge. The programme is particularly innovative in its cooperation and standardisation from-the-start approach, helping to prevent unnecessary duplication and harmonisation efforts in the future, and taking full advantage of shared expertise and best practices to make advancements for the benefit of all.

At present, pollen data are practically unavailable for the general public, as well as global programmes such as the WMO and WHO. The establishment of an automated monitoring network will facilitate the transition of pollen observations from privately run initiatives to part of the world-wide effort on environmental monitoring with clear financing schemes. This will ensure the long-term sustainability of observation networks, timely availability of information for endusers, and high temporal resolution data that will open up new research avenues, allowing a much deeper understanding of, for example, aerobiological processes. Furthermore, there is potential to use some of the same instruments for air quality observations, possibly providing further areas of synergy and cost reduction in the domain of atmospheric monitoring.

Acknowledgements The authors, who helped initiate the AutoPollen programme, would warmly likely to thank all AutoPollen members for their participation and engagement. The authors would also like to thank the Copernicus CAMS-23 project, with whom the EUMETNET AutoPollen programme collaborates. MS acknowledges the Academy of Finland project PS4A "Biotieteiden ja Ympäristön Tutkimuksen Toimikunta" (Project Number 318194).

Open Access This article is licensed under a Creative Commons Attribution 4.0 International License, which permits use, sharing, adaptation, distribution and reproduction in any medium or format, as long as you give appropriate credit to the original author(s) and the source, provide a link to the Creative Commons licence, and indicate if changes were made. The images or other third party material in this article are included in the article's Creative Commons licence, unless indicated otherwise in a credit line to the material. If material is not included in the article's Creative Commons licence and your intended use is not permitted by statutory regulation or exceeds the permitted use, you will need to obtain permission directly from the copyright holder. To view a copy of this licence, visit http://creativecommons.org/licenses/by/4.0/.

\section{References}

Beggs, P. (2010). Adaptation to impacts of climate change on aeroallergens and allergic respiratory diseases. International Journal of Environmental Research and Public Health, 7, 3006-3021.

Buters, J. T. M., Antunes, C., Galveias, A., Bergmann, K. C., Thibaudon, M., Galan, C., et al. (2018). Pollen and spore monitoring in the world. Clinical and Translational Allergy, 8, 9-9.

CEN EN 16868:2019. Ambient air-Sampling and analysis of airborne pollen grains and fungal spores for networks related to allergy - Volumetric Hirst method.

Chappuis, C., Tummon, F., Clot, B., Konzelmann, T., Calpini, B., \& Crouzy, B. (2019). Automatic pollen monitoring: First insights from hourly data. Aerobiologia, 36, 159-170.

Crouzy, B., Stella, M., Konzelmann, T., Calpini, B., \& Clot, B. (2016). All-optical automatic pollen identification: Towards an operational system. (2016). Atmospheric Environment, 140, 202-212.

de Weger, L. A., Pashley, C. P., Sikoparija, B., Skjoth, C. A., Kasprzyk, I., Grewling, L., et al. (2016). The long distance transport of airborne Ambrosia pollen to the UK and the Netherlands from Central and south Europe. International Journal of Biometeorology, 60, 1829-1839.

D'Amato, G., \& Cecchi, L. (2008). Effects of climate change on environmental factors in respiratory allergic diseases. Clinical and Experimental Allergy, 38, 1264-1274.

D’Amato, G., Bergmann, K. C., Cecchi, L., Annesi-Maesano, I., Sanduzzi, A., Liccardi, G., et al. (2014). Climate change and air pollution-Effects on pollen allergy and other allergic respiratory diseases. Allergology Journal International, 23, 17-23.

ERS, White Book (2013). www.erswhitebook.org.

Galan, C., Smith, M., Thibaudon, M., Frenguelli, G., Oteros, J., Gehrig, R., et al. (2014). Pollen-monitoring: Minimum requirements and reproducibility of analysis. Aerobiologia, 30, 385-395.

GEO. (2009). Critical Earth Observation Priorities for Human Health (GEO TASK US-09-01a): Aeroallergens Societal Benefits Area. Final Report, 53 p.

Gilles, S., Blume, C., Wimmer, M., Damialis, A., Meulenbroek, L., Gökkaya, M., et al. (2020). Pollen exposure weakens innate defense against respiratory viruses. Allergy, 75, $576-587$.

Hirst, J. M. (1952). An automatic volumetric spore trap. Annals of Applied Biology, 39, 257-265.

Huffman, J. A., Perring, A. E., Savage, N. J., Clot, B., Crouzy, B., Tummon, F., et al. (2019). Real-time sensing of bioaerosols: Review and current perspectives. Aerosol Science and Technology, 54, 465-495.

IPCC 4th Assessment Report, contributing authors: Confalonieri, U., Menne, B., Akhtar, R., Ebi, K.L., Hauengue, M., Kovats, R.S., Revich, B., and Woodward, A., (2007). Climate Change 2007: Impacts, Adaptation and Vulnerability. Contribution of Working Group II to the Fourth Assessment Report of the Intergovernmental Panel on Climate Change, M.L. Parry, O.F. Canziani, J.P. Palutikof, P.J. van der Linden and C.E. Hanson, Eds., Cambridge University Press, Cambridge, UK, pp. 391-431. 
Izquierdo, R., Belmonte, J., Avila, A., Alarcón, M., Cuevas, E., \& Alonso-Pérez, S. (2011). Source areas and long-range transport of pollen from continental land to Tenerife (Canary Islands). International Journal of Biometeorology, 55, 67-85.

Kawashima, S., Clot, B., Fujita, T., Takahashi, Y., \& Nakamura, K. (2007). An algorithm and a device for counting airborne pollen automatically using laser optics. Atmospheric Environment, 41, 7987-7993.

Kawashima, S., Thibaudon, M., Matsuda, S., Fujita, T., Lemonis, N., Clot, B., \& Oliver, G. (2017). Automated pollen monitoring system using laser optics for observing seasonal changes in the concentration of total airborne pollen. Aerobiologia. https://doi.org/10.1007/s10453-017-9474-6

Laatikainen, T., von Hertzen, L., Koskinen, J. P., Mäkelä, M. J., Jousilahti, P., Kosunen, T. U., et al. (2011). Allergy gap between Finnish and Russian Karelia on increase. Allergy, 66, 886-892.

Lake, I. R., Jones, N. R., Agnew, M., Goodess, C. M., Giorgi, F., Hamaoui-Laguel, L., et al. (2017). Climate change and future pollen allergy in Europe. Environmental Health Perspectives, 125, 385-391.

Lucas, R., Bunderson, L., Allan, N., \& Lambson, K. (2018). Automated airborne particulate matter collection, imaging, identification, and analysis. US Patent WO2016073745A3, filed November 5, 2015, and issued September 29, 2016.

Mohanty, R. P., Buchheim, M. A., Anderson, J., \& Levetin, E. (2017). Molecular analysis confirms the long-distance transport of Juniperus ashei pollen. PLoS ONE, 12, $\mathrm{e} 0173465$.

Oberpriller, Q., Vettori, A., \& Iten, R. (2017). Nutzen real-time Pollendaten (p. 50p). Bern: INFRAS.

O'Connor, D. J., Healy, D. A., Hellebust, S., Buters, J. T. M., \& Sodeau, J. R. (2014). Using the WIBS-4 (waveband integrated bioaerosol sensor) technique for the on-line detection of pollen grains. Aerosol Science and Technology, 48, 4.

Oteros, J., Buters, J., Laven, G., Röseler, S., Wachter, R., Schmidt-Weber, C., \& Hofmann, F. (2017). Errors in determining the flow rate of Hirst-type pollen traps. Aerobiologia, 33, 201-210.

Oteros, J., Pusch, G., Weichenmeier, I., Heimann, U., Möller, R., Röseler, S., et al. (2015). Automatic and online pollen monitoring. International Archives of Allergy and Immunology, 167, 158-166.

Oteros, J., Sofiev, M., Smith, M., Clot, B., Damialis, A., Prank, M., et al. (2019). Building an automatic pollen monitoring network (ePIN): Selection of optimal sites by clustering pollen stations. Science of the Total Environment, 688, 1263-1274.

Pearce, N., Ait Khaled, N., Beasley, R., Mallol, J., Keil, U., Mitchell, E., \& Robertson, C. (2007). Worldwide trends in the prevalence of asthma symptoms: Phase III of the International Study of Asthma and Allergies in Childhood (ISAAC). Thorax, 62, 758-766.

Riedl, M., \& Diaz-Sanchez, D. (2005). Biology of diesel exhaust effects on respiratory function. Journal of Allergy and Clinical Immunology, 115, 221-228.

Rönmark, E., Bjerg, A., Perzanowski, M., Platts-Mills, T., \& Lundbäck, B. (2009). Major increase in allergic sensitization in school children from 1996 to 2006 in Northern
Sweden. Journal of Allergy and Clinical Immunology, 124, $1-19$.

Ronneberger, O., Schultz, E., \& Burkhardt, H. (2002). Automated pollen recognition using $3 \mathrm{D}$ volume images from fluorescence microscopy. Aerobiologia, 18, 107-115.

Rousseau, D. D., Schevin, P., Ferrier, J., Jolly, D., Andreasen, T., Ascanius, S. E., et al. (2008). Long-distance pollen transport from North America to Greenland in spring. Journal of Geophysical Research: Biogeosciences, 113, G2.

Šantl-Temkiv, T., Sikoparija, B., Maki, T., Carotenuto, F., Amato, P., Yao, M., et al. (2019). Bioaerosol field measurements: Challenges and perspectives in outdoor studies. Aerosol Science and Technologies. https://doi.org/10. 1080/02786826.2019.1676395

Šaulienè, I., Šukiene, L., Daunys, G., Valiulis, G., Vaitkevičius, L., Matavulj, P., et al. (2019). Automatic pollen recognition with the Rapid-E particle counter: The first-level procedure, experience and next steps. Atmospheric Measurement Techniques, 12, 3435-3452.

Sauvageat, E., Zeder, Y., Auderset, K., Calpini, B., Clot, B., Crouzy, B., et al. (2020). Real-time pollen monitoring using digital holography. Atmospheric Measurement Techniques, 13, 1539-1550.

Savage, N. J., Krentz, C. E., Könemann, T., Han, T. T., Mainelis, G., Pöhlker, C., \& Huffman, J. A. (2017). Systematic characterization and fluorescence threshold strategies for the wideband integrated bioaerosol sensor (WIBS) using size-resolved biological and interfering particles. Atmospheric Measurement Techniques, 10, 4279-4302.

Schaffner, U., Steinbach, S., Sun, Y., Skoth, C. A., de Weger, L. A., Lommen, S. T., et al. (2020). Biological weed control to relieve millions from Ambrosia allergies in Europe. Nature Communications. https://doi.org/10.1038/s41467-02015586-1

Sofiev, M., Berger, U., Prank, M., Vira, J., Arteta, J., Belmonte, J., et al. (2015). MACC regional multi-model ensemble simulations of birch pollen dispersion in Europe. Atmospheric Chemistry and Physics, 15, 8115-8130.

Sofiev, M., Ritenberga, O., Albertini, R., Arteta, J., Belmonte, J., Bonini, M., et al. (2017). Multi-model ensemble simulations of olive pollen distribution in Europe in 2014. Atmospheric Chemistry and Physics, 17, 12341-12360.

Sofiev, M. (2019). On possibilities of assimilation of near-realtime pollen data by atmospheric composition models. Aerobiologia, 35, 523-531.

Sunyer, J., Jarvis, D., Pekkanen, J., Chinn, S., Janson, C., Leynaert, B., et al. (2004). Geographic variations in the effect of atopy on asthma in the European Community Respiratory Health Study. Journal of Allergy and Clinical Immunology, 114, 1033-1039.

Ziska, L. H., Makra, L., Harry, S. K., Bruffaerts, N., Hendrickx, M., Coates, F., et al. (2019). Temperature-related changes in airborne allergenic pollen abundance and seasonality across the northern hemisphere: A retrospective data analysis. The Lancet Planetary Health, 3, e124-e131.

Zuberbier, T., Lötvall, J., Simoens, S., Subramanian, S. V., \& Church, M. K. (2014). Economic burden of inadequate management of allergic diseases in the European Union: A GA2LEN review. Allergy, 69, 1275-1279. 